\title{
Coaction vs. Reciprocal Cooperation Among Unrelated Individuals in Social Cichlids
}

\author{
Michael Taborsky* and Thomas Riebli \\ Division of Behavioural Ecology, Institute of Ecology and Evolution, University of Bern, Bern, Switzerland
}

Members of social groups often temporally coordinate their behaviors, for instance in defense or foraging. In the context of cooperation, simultaneous or sequential coordination of behavior may allow social partners to adjust their cooperative effort quickly among each other. By manipulating individual behaviors, here we tested experimentally whether unrelated brood care helpers of the cichlid fish Neolamprologus pulcher would cooperate in dyads when enabled to dig out a joint shelter or to defend their territory against a predator. Both the digging and defense efforts of social partners were contingent on each other's investment, and the test subjects temporally coordinated these behaviors. Remarkably, the direction of conditional responses to each other's

OPEN ACCESS

Edited by:

Rufus Johnstone,

University of Cambridge,

United Kingdom

Reviewed by:

Riva Riley,

Queen Mary University of London, United Kingdom

Sheng-Feng Shen,

Biodiversity Research Center,

Academia Sinica, Taiwan

*Correspondence:

Michael Taborsky

michael.taborsky@iee.unibe.ch

Specialty section:

This article was submitted to

Social Evolution,

a section of the journal

Frontiers in Ecology and Evolution

Received: 23 July 2019 Accepted: 18 December 2019

Published: 21 January 2020

Citation:

Taborsky M and Riebli T (2020)

Coaction vs. Reciprocal Cooperation

Among Unrelated Individuals in Social

Cichlids. Front. Ecol. Evol. 7:515.

doi: 10.3389/fevo.2019.00515 cooperative investment diverged between the two chosen experimental time frames, which tested for coaction and reciprocity. Test subjects reduced their own digging and defense efforts while their partners were showing these behaviors themselves, implying that they did not exert coaction but rather economized on their investment. In contrast, if a social partner had helped to dig out the common shelter in a previous time period, focal test fish advanced their digging effort in the subsequent experimental phase, which indicates reciprocal cooperation. Social partners also coordinated shelter use when they could see each other, especially after they had been visually exposed to a predator. Our results reveal coordination of cooperative behaviors among unrelated social partners, which has not yet been experimentally demonstrated in cooperatively breeding vertebrates.

Keywords: behavioral coordination, reciprocity, social facilitation, cooperative breeding, social evolution, tragedy of the commons

\section{INTRODUCTION}

Group members interact in many different contexts, for instance in foraging, mate attraction, predator avoidance, territory defense, and brood care (Taborsky, 1984, 2016; Dugatkin, 1997; Clutton-Brock et al., 2001; Eberle and Kappeler, 2006; Székely et al., 2010). They may coordinate the timing and quantity of behaviors among each other to reduce costs or increase benefits (Fernandez-Juricic et al., 2004; Lewis et al., 2004). Coordination of behaviors implies an explicit influence of the timing and/or amount of the behavior between individuals (Coussi-Korbel and Fragaszy, 1995). Behavioral coordination occurs for instance in vigilance, territory defense and feeding behavior (Galloway et al., 2005; Pays et al., 2007; Hall and Peters, 2008). While the frequencies of behaviors are often not affected, the temporal pattern of behavior is adjusted among social 
partners. For instance, eastern gray kangaroos (Macropus giganteus) and Defassa waterbucks (Kobus ellipsiprymnus defassa) synchronize the onsets and ends of scanning bouts between group members, which then produces waves of collective vigilance (Pays et al., 2007).

If animals cooperate, for instance in the context of foraging or predator avoidance, they may coordinate same or different behaviors using a continuous flow of information between interacting partners (van Doorn et al., 2014). Coordinated cooperation, where the help of one individual is contingent on that of another (Dugatkin, 2002), may happen either simultaneously or sequentially. Simultaneous cooperation, where individuals help each other at the same time, can be achieved for instance through social facilitation, which has been classified as a form of social learning (Zajonc, 1965; Brown and Laland, 2003; Karplus et al., 2007). Generally, simultaneous behavioral coordination has been referred to as "isomorphic coordination" due to the behavioral similarity between individuals (CoussiKorbel and Fragaszy, 1995). On the proximate level, such coordination does not require highly advanced cognitive abilities like specific memory or individual recognition (Dugatkin, 2002; Stevens and Hauser, 2004), and on the ultimate level it is easy to avoid to be cheated because reactions to non-cooperative behavior can be immediate (van Doorn et al., 2014). Alternatively, cooperation between individuals can also happen sequentially, which allows the reaction to received cooperative or deceptive behavior to occur after a time delay. On the ultimate level, in order to stabilize cooperation, particular mechanisms are needed to prevent cheating (Lehmann and Keller, 2006; Taborsky et al., 2016). On the proximate level, such reciprocity mechanisms may require specific memory and individual recognition (Milinski and Wedekind, 1998; Stevens et al., 2005), except in generalized reciprocity, which applies simpler decision rules (Hamilton and Taborsky, 2005; Pfeiffer et al., 2005; Nowak and Roch, 2007; Rutte and Taborsky, 2007; Rankin and Taborsky, 2009; Barta et al., 2011; van Doorn and Taborsky, 2012; Gfrerer and Taborsky, 2017; Stojkoski et al., 2018).

A recent model suggests that with increasing time delays between the actions of different players, contingent cooperation becomes less likely to fulfill the conditions of evolutionary stability (van Doorn et al., 2014). Cooperation by coaction does not require that individuals initiating cooperation pay in advance for uncertain future benefits, because they can respond immediately to the cooperative or non-cooperative behavior of their partner. Instead, when a delay is introduced to information transfer between players about each other's helpfulness, the effect is equivalent to increasing the costs of cooperation. The situation then resembles a discrete-time alternating prisoner's dilemma. This model revealed that coaction and reciprocity are connected by a continuum of opportunities for real-time information exchange (van Doorn et al., 2014). It predicts that a simultaneous exchange of helpful behaviors (coaction) is more likely to occur than an exchange of cooperative actions that are separated by time delays (reciprocity).

Here we tested in a stepwise approach whether experimental dyads of unrelated individuals of the cooperatively breeding cichlid Neolamprologus pulcher show coordinated cooperation both simultaneously (coaction) and consecutively (reciprocity). We measured the cooperative actions of members of experimental dyads regarding territory maintenance, i.e., removal of sand from a common shelter, and defense against a predatory fish. In this species, groups of related and unrelated fish exhibit high levels of collaboration and division of labor (Taborsky and Limberger, 1981; Dierkes et al., 2005; Stiver et al., 2005; Bruintjes and Taborsky, 2011; Taborsky, 2016). The dominant individuals in a group largely monopolize reproduction, while subordinates share in all duties of parental care and territory maintenance, including direct egg care, the removal of sand from shelters, and the defense of the territory against predators and competitors (Taborsky and Limberger, 1981; Taborsky, 1984; Taborsky and Grantner, 1998; Bruintjes and Taborsky, 2011; Jungwirth et al., 2015).

In a first experiment we checked whether the test fish coordinated behaviors simultaneously (coaction). By either restricting or allowing visual contact between two social partners we predicted that the individuals would temporally coordinate cooperative behaviors (sand removal and defense against a predator) simultaneously if they had visual contact. Additionally, we tested whether the perceived risk of predation modulates frequencies and coordination of cooperative behaviors. In a second step we tested whether the social partners coordinate cooperative behaviors sequentially (reciprocity). We tested both the temporal pattern and the quantity of cooperative behaviors shown by focal individuals after witnessing their partners either participating in a cooperative task or not. We predicted that previously experienced cooperation by the social partner would significantly affect the propensity to cooperate in the focal individual. We focussed on behaviors that are considered to be cooperative and costly either because of energetic expenses or risk, i.e., territory maintenance and defense (Taborsky, 1984, 1985; Grantner and Taborsky, 1998; Taborsky and Grantner, 1998; Heg and Taborsky, 2010). Individual recognition is often a prerequisite for sequential cooperation, and this ability has been demonstrated experimentally in N. pulcher (Hert, 1985; Balshine-Earn and Lotem, 1998).

\section{METHODS}

\section{Experimental Fish}

The study species, Neolamprologus pulcher, is a small, cooperatively breeding cichlid endemic to Lake Tanganyika, East Africa (Duftner et al., 2007), which feeds mainly on zooplankton (Gashagaza, 1988). This highly social species uses self-dug burrows, small holes and crevices as shelters and breeding substrate (Taborsky and Limberger, 1981; Heg et al., 2005). Breeding groups consist of a dominant breeding pair and several helpers of both sexes and of a broad size range, from small immature individuals to mature fish fully capable of independent breeding (Balshine et al., 2001). These helpers actively engage in territory maintenance, territory defense and brood care (Taborsky and Limberger, 1981; Taborsky, 1984; Bruintjes and Taborsky, 2011). Due to high predation pressure there is a high breeder turn-over in $N$. pulcher, which means that large helpers 
often care for non-kin broods (Taborsky and Limberger, 1981; Taborsky, 1984; Brouwer et al., 2005; Dierkes et al., 2005; Stiver et al., 2005).

The fish used for this study were laboratory-reared offspring of wild caught animals from the southern end of Lake Tanganyika near Mupulungu. They were kept in aggregations including fish of both sexes in 400 -liter aquaria at $27 \pm 1^{\circ} \mathrm{C}$. Water quality was held close to the values of Lake Tanganyika (Taborsky, 1984), and the light regime was 13:11 h (light:dark). The fish were fed once a day with commercial dry food (Tetramin) four times per week, and twice a week with frozen food (daphnia, Artemia salina nauplia and a mix of vegetables).

The experiments were conducted under the animal experimentation license 40/05 of the Veterinary Office of the Canton Bern, Switzerland.

\section{Experimental Procedure}

The two experiments performed in this study testing for coaction and reciprocity, respectively, used the same aquarium set-up but different individuals. The experimental 100 liter aquarium was divided by clear Plexiglas plates, arranged in a T-shaped manner, into one 50 liter compartment $(100 * 25 * 40 \mathrm{~cm}$; length * width * height) at the back of the tank, and two 25 liter $(25 * 25 * 40 \mathrm{~cm})$ compartments in the front of the tank. We put the predator stimulus fish (predator of N. pulcher, Lepidiolamprologus elongatus; Heg et al., 2004; Groenewoud et al., 2016) into the larger 50 liter compartment, and the two test fish (size- matched $N$. pulcher of equal sex) were individually put into the two smaller 25 liter compartments. In order to reduce stress and prevent habituation of the focal test fish, sight into the predator compartment was restricted by removable, opaque partitions that were installed during non-experimental times. To provide a shelter that was jointly used by both test fish, an opaque PVC sheet was leaned against the clear compartment divider from both sides in the respective test fish compartments (Figure 1). Thereby, the test fish had visual but no physical contact to each other, i.e., they shared the shelter without being able to overtly attack or harm each other (see Figure 1A). In order to provide shelter to the predator, an opaque PVC sheet was leaned against the back wall of the predator compartment. Air stones were put into both $N$. pulcher compartments and an air driven biological filter was placed in the predator compartment to maintain good water quality and oxygen supply. The predators were used only for the coaction experiment; afterwards they were transferred back into their respective holding tanks. Behavioral observations were recorded using "The Observer 3.0" Software (Noldus Information Technology, Wageningen, The Netherlands).

\section{Coaction Experiment}

The aim of the first experiment was to test whether territory maintenance (removal of sand from a common shelter), antipredator aggression (overt aggression and aggressive displays) and hiding behavior of $N$. pulcher are affected by the behavior of a social partner. This was done to check if the fish responded to the quantity of territory maintenance and defense of their partner, and whether they temporally coordinated these behaviors among each other.

We used unrelated fish $(N=64)$ that were randomly caught from aggregation tanks and measured in size (standard length, SL: tip of the snout to the basis of the tail fin; mean \pm SD: 48.5 $\pm 3.5 \mathrm{~mm}$; range: $40.5-55.5 \mathrm{~mm}$ ) and weight (mean \pm SD: 3280 $\pm 679 \mathrm{mg}$ ). Their sex (32 females and 32 males) was determined by inspection of the genital papilla. Test dyads were matched for sex and size with a maximum size difference of $1 \mathrm{~mm}$. They were introduced into the test aquarium 4 days before the experiment started, allowing them to get accustomed (see Figure 1A). Six experimental dyads had to be terminated before the experiment started due to high levels of aggression displayed between the test fish (one individual constantly attacking the compartment partition; four male and two female dyads).

First, we tested whether the observation of a social partner engaging in a cooperative task (sand removal) increases the motivation of the focal test fish to participate in the same task. Second, we tested whether perceived risk of predation would modify this motivation. We opted to check the baseline motivation of the fish engaging in sand removal by adding sand into the shelter. This was done without social cues by preventing visual contact between the test fish with an opaque barrier ("Control"; Figure 1A). After removing the visual barrier, we checked with a second sand addition trial ("Sand 1"; Figure 1A) whether social cues (test fish with visual contact) change the motivation to engage in excavating the shelter.

To test for cooperative territory defense against a predator, we exposed the test fish $2 \mathrm{~h}$ later to a predatory fish to induce defense behavior. Again, the test fish had either visual contact with each other ("Predator 1"; Figure 1A) or not ("Predator 2"; Figure 1A) to test for the potential influence of behavioral coordination among them. Finally, we tested whether this predator exposure had longer lasting effects. The underlying hypothesis was that it could raise the demand for safety, which might lead to an increase in digging frequencies at a later stage. Thus we performed a third sand addition trial, again with visual contact ("Sand 2"; Figure 1A) or without ("Sand 3"; Figure 1A). Generally, we predicted that the amount and coordination of cooperative behaviors (sand removal and defense) depend on the visual contact between the social partners and the behavior each partner displays, with higher frequencies of coordinated behavior if the partners can see each other ("Control" vs. "Sand 1"; "Predator 1" vs. "Predator 2"; "Sand 2" vs. "Sand 3"; Figure 1A). Moreover, we predicted that simulated predation exposure would increase the demand for safety, thereby raising digging frequencies between corresponding digging trials before and after the predator exposure (partner not visible: "Control" vs. "Sand 3" and partner visible: "Sand 1" vs. "Sand 2"; Figure 1A). Thus, we predicted digging frequencies to be highest if the focal test fish had visual contact with each other after perceiving a potential threat. Further experimental detail including the time lapse is explained below.

All experimental dyads $(N=26)$ started with the first sand addition trial ("Control"), which served as baseline condition. Focal observations in all experiments lasted for $10 \mathrm{~min}$ (see also time line Figure 1A). Ten minutes prior to the focal observations, 
A

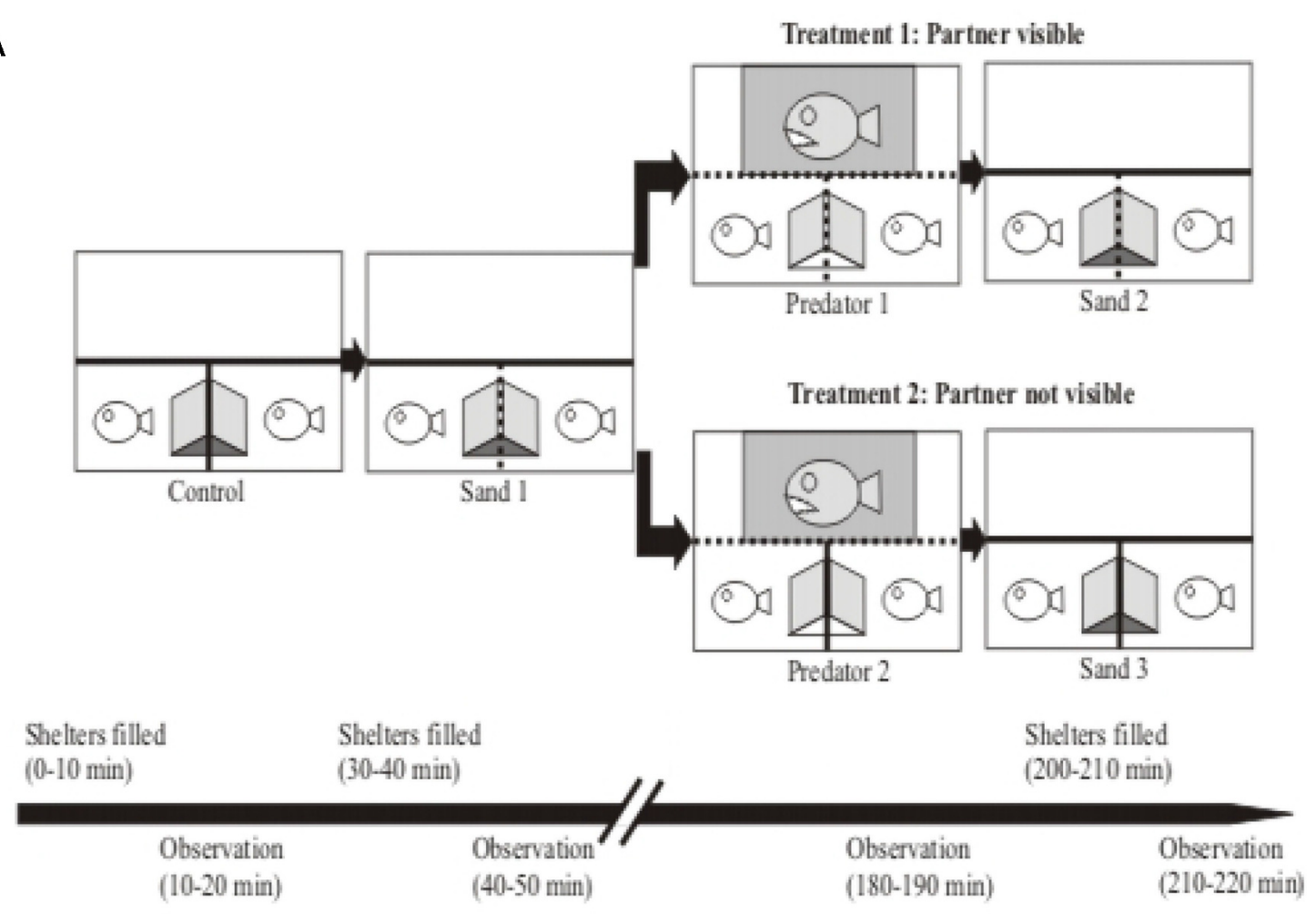

B

\section{Helping Treatment}

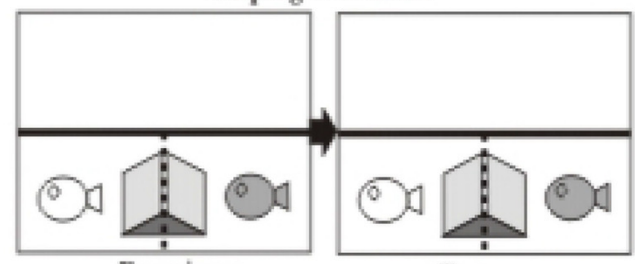

Experience

Defection Treatment

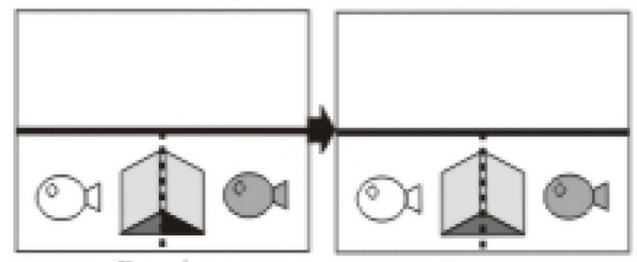

Experience

Test
C D E

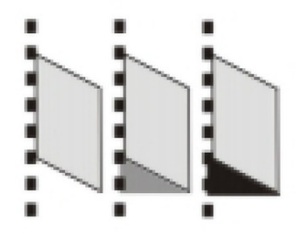

Shelters filled

Shelters filled

(0-10 minin)

(30-40 min)

Observation

(10-20 min)
Observation

(40-50 min)

FIGURE 1 | Sketch of experimental tanks (top view) and procedures of the coaction and reciprocity experiments. (A) Coaction Experiment. The small white fish icons depict the two focal test fish and the big gray fish icon represents the predator used as stimulus in the predator presentations. The two test fish ( $N=26$ dyads) each used a shelter created by an opaque PVC slate leaned against the partition separating the two compartments. This partition was either opaque (depicted by a solid line; "Control" and "Treatment 2") or clear (depicted by a dotted line; "Sand 1" and "Treatment 1"), so in the latter case the test fish perceptually shared a common shelter. Except during predator presentations ("Predator 1" and "Predator 2"), at the beginning of each experimental period the shelters were filled with sand to provide incentives for burrowing behavior. After the first two phases the experimental dyads were assigned to either Treatment 1 (test fish had visual contact; $N=14$ ) or to 
FIGURE 1 | Treatment 2 (test fish had no visual contact; $N=12$ ). The shaded area in the "Predator 1" and "Predator 2" phases represents the area in which the predator was presented to the focal test fish. Experimental manipulations are depicted in the time line at the bottom; please see main text for details. (B) Reciprocity Experiment. The white fish icon depicts the focal test fish and the gray fish icon its partner. The experimental dyads were randomly assigned either to the Helping Treatment $(N=18)$ or to the Defection Treatment $(N=15)$. Experimental manipulations are depicted in the time line at the bottom; please see main text for details. Outfit: Shelters consisted of opaque PVC sheets $(10 \times 10 \mathrm{~cm})$ leaned against the compartment dividers. Differently colored shelters depict different accessibilities of shelters in both experiments: (C) shelter empty, (D) shelter experimentally filled with sand, (E) shelter filled with sand and entrance blocked by a clear Plexiglas triangle. Overall, opaque compartment dividers are depicted by solid lines, clear dividers by dotted lines.

a visual barrier (opaque PVC sheet) was installed between the test fish in order to prevent visual contact between them, and shelters were filled with sand by the experimenter. Ten minutes later the focal observations were started. At the end of this experimental phase, the remaining sand was entirely removed by the experimenter, and the visual barrier was removed from the tank. After a break of $10 \mathrm{~min}$, the second experimental period began by adding sand into the focal individual's shelters ("Sand 1"). Ten minutes later the focal observations of the test fish were started. After the end of these observations the sand was removed from the shelter entirely. A break of $2 \mathrm{~h}$ followed this second experimental period.

To test whether visual contact to a social partner affects defense behavior against a predator, and whether perceived predation risk modifies digging and hiding behavior, experimental dyads were randomly assigned to one of two treatments, with or without permanent visual contact between the focal test fish ("Treatment 1," $N=14$; and "Treatment 2," $N$ $=12$, respectively; see Figure 1A).

Before the test fish were exposed to the predator ("Predator 1 " or "Predator 2"), clear Plexiglas partitions were installed in the predator's compartment in order the keep the predator to a confined area during its exposure to the test fish (see Figure 1A). Additionally, the predator's shelter was removed during the predator exposure to assure that it was permanently within sight of the test fish. Behavioral observations were started right after the removal of the opaque barrier between the predator and the test fish compartments. Ten minutes later behavioral observations were terminated by reinstalling the opaque barrier between the test fish and the predator. The shelter for the predator was put back into the compartment and the two clear Plexiglas sheets that kept the predator in the presentation area were removed. After a break of $10 \mathrm{~min}$, the shelters of the test fish were prepared for the last sand addition trial by filling them with sand, and observations were started after 10 min ("Sand 2" or "Sand 3"). After these observations, the sand was removed from the shelter and the fish were left undisturbed for at least $24 \mathrm{~h}$ until they were put back into the aggregation tanks from which they were initially caught.

In all observations we recorded latencies and frequencies of aggressive displays (head-down display, s-bending, opercula spreading, spreading of fins; see Taborsky, 1984 for a brief ethogram) and overt aggression (mouth contact with Plexiglas partition with apparent intention to attack the fish on the other side) against the predator. As a measure of territory maintenance, we recorded the latencies and time intervals between subsequent events of sand clearance (removal of sand with the mouth or through strong tail fin strokes). To estimate the perceived need for safety, we measured the frequency of hiding in the shelter during predator exposure tests, and the frequency of close distance approaches to shelter entrances $(<5 \mathrm{~cm}$, without hiding in the shelter) during sand addition trials.

\section{Reciprocity Experiment}

In the second experiment we tested for long-term effects of observing a partner engaging in cooperative behavior. The test dyads were composed and treated in the same way as in the coaction experiment, but different fish were used. In total, 72 individuals were caught from their storage tanks and measured in size (SL; mean \pm SD: $49.0 \pm 3.5 \mathrm{~mm}$; range: $41.5-56.0 \mathrm{~mm}$ ) and weight (mean \pm SD: $3370 \pm 696 \mathrm{mg}$; range: $2125-4630 \mathrm{mg}$ ). Gender was determined by inspection of the genital papilla (36 males and 36 females).

We randomly assigned the test dyads either to the helping $(N=18)$ or the defection treatment $(N=15$; due to persistent aggression, three dyads were excluded from the experiments: two male, one female dyad; see Figure 1B). Again, test dyads were acclimatized to the experimental tanks for 4 days before the experiment started. In contrast to the Coaction Experiment, in the Reciprocity Experiment the test subjects were habituated to enhanced digging demands by filling their shelters on days 3 and 4 of the acclimatization period 5 times/day with sand, which was removed each time after $20 \mathrm{~min}$. On the experimental day (day 5), each treatment consisted of an "Experience" and a "Test" phase. We randomly chose which individual would serve as focal test fish and as partner. During the experience phase the latter was either allowed to dig ("helping treatment") or not ("defection treatment"). Like in the coaction experiment, we always filled the shelters with sand $10 \mathrm{~min}$ prior to the behavioral observations, and we removed the sand from the shelter immediately after the observations and allowed the fish to recover for $10 \mathrm{~min}$ thereafter.

In the helping treatment both fish were allowed to dig in both experimental phases, experience and test phase, whereas in the defection treatment we blocked the shelter entrance of the partner in the experience phase with clear Plexiglas triangles to prevent it from accessing the sand in its shelter. Afterwards in the test phase, both fish were again allowed to participate in sand removal behavior.

\section{Data Analysis Coaction Experiment}

Mann-Whitney U-tests were used to check for behavioral differences between the sexes. As there were no significant differences between sexes, we combined them in all further analyses. To examine behavioral data of the test fish (digging, shelter approach, aggression toward predator, and hiding 
TABLE 1 | Digging and shelter approach frequencies of focal fish before and after the predator presentation, depending on the social partners' behavioral frequencies and partner visibility of the coaction experiment.

\begin{tabular}{lcccc}
\hline Parameter & z-value & P-value & \multicolumn{2}{c}{ Coefficient \pm SE } \\
\hline Model 1: Digging Frequency of test fish & & & \\
Intercept & -4.883 & $<\mathbf{0 . 0 0 1}$ & -3.170 & 0.650 \\
Partner digging frequency & -3.388 & $<\mathbf{0 . 0 0 1}$ & -0.033 & 0.010 \\
Predator presentation & 8.450 & $<\mathbf{0 . 0 0 1}$ & 2.453 & 0.290 \\
Visibility partner & 6.061 & $<\mathbf{0 . 0 0 1}$ & 1.351 & 0.223 \\
Presentation *Visibility & -5.736 & $<\mathbf{0 . 0 0 1}$ & -2.018 & 0.352 \\
Model 2: Shelter approaches of test fish & & & \\
Intercept & 8.688 & $<\mathbf{0 . 0 0 1}$ & 1.322 & 0.152 \\
Partner approaching frequency & 3.140 & $\mathbf{0 . 0 0 2}$ & 0.046 & 0.147 \\
Predator presentation & -0.091 & 0.927 & -0.013 & 0.138 \\
Visibility partner & 0.381 & 0.704 & 0.040 & 0.104 \\
Presentation *Visibility & -0.438 & 0.661 & -0.090 & 0.200 \\
\hline
\end{tabular}

Predator presentation (before, after presentation) and visual contact (partner visible, invisible), and their interaction were used as fixed effects. Fish identity nested within group identity was used as random effect.

All models were fitted by the Laplace approximation. Predator presentation (before) and partner visibility (invisible) were used as reference categories with their coefficients set at zero. Digging frequency of the experimental partner was treated as covariate. Significant $p$-values at an $\alpha$-level of 0.05 are shown in bold.

frequencies), general linear mixed models (Poisson distributed, log-link; Bates and Maechler, 2010) were used, adding the partner's behavior (digging, shelter approaches, or hiding frequency, respectively), whether the fish already experienced the predation threat (before or after presentation; Models 1 and 2; Table 1), whether the test fish had visible contact or not (see also Models 3 and 4; Table 2), and the interaction between visible contact and predator experience, as fixed effects. Fish identity nested within group identity was used as random effect in order to account for repeated measurements. In order to test for behavioral coordination between the test fish we scrutinized the total observation period in intervals of $10 \mathrm{~s}$ and applied the Olmstead corner test for association (Olmstead and Tukey, 1947).

\section{Reciprocity Experiment}

General linear mixed-effects models (Poisson distributed, log-link; Bates and Maechler, 2010) were used to test the focal individual's digging frequency, the interval between subsequent digging bouts, and the latency to initiate a digging bout after the partner has finished their digging bout; treatment (i.e., "helping" or "defection" in the preceding experience phase), experimental phase and its interaction were added as fixed effects (Models 1 and 2; Table 3). As the partner was not allowed to participate in digging during the experience phase of the defection treatment, we compared the focal's latency to start a digging bout after the partner had finished one of both experience phases (3 level Factor; Model 3; Table 3). Finally, we added the partners' digging frequency as covariate to check for correlations between the digging frequencies of the two fish (Model 4; Table 3). Again, total observation period was split into $10 \mathrm{~s}$ intervals to test for
TABLE 2 | Aggression toward predator, and hiding frequencies of focal fish during the predator presentation in the coaction experiment, depending on the experimental partners' behavioral frequencies and partner visibility.

\begin{tabular}{lcccc}
\hline Parameter & z-value & P-value & \multicolumn{2}{l}{ Coefficient $\mathbf{~ S E}$} \\
\hline Model 3: Aggression toward & predator of test fish & & \\
Intercept & 10.063 & $<\mathbf{0 . 0 0 1}$ & 2.964 & 0.295 \\
Partner aggression frequency & 2.773 & $\mathbf{0 . 0 0 6}$ & 0.010 & 0.004 \\
Visibility partner & 3.148 & $\mathbf{0 . 0 0 2}$ & 1.544 & 0.491 \\
Partner aggression * Visibility & -3.904 & $<\mathbf{0 . 0 0 1}$ & -0.024 & 0.006 \\
Model 4: Hiding frequency of test fish & & & \\
Intercept & 8.790 & $<\mathbf{0 . 0 0 1}$ & 2.719 & 0.309 \\
Partner approaching frequency & 1.316 & 0.188 & 0.013 & 0.010 \\
Visibility partner & -0.264 & 0.792 & -0.147 & 0.556 \\
Partner hiding * Visibility & 0.288 & 0.773 & 0.005 & 0.017
\end{tabular}

Visual contact (partner visible, invisible) and the interaction between the partner's behavioral frequencies and visibility were used as fixed effects. Fish identity nested within group identity was used as random effect.

All models were fitted by the Laplace approximation. Partner "invisible" condition was used as reference category with its coefficient set at zero. Aggression and hiding frequency of social partner was treated as covariate. Significant p-values at an $\alpha$-level of 0.05 are shown in bold.

temporal coordination between digging frequencies of both fish using the Olmstead corner test for association (Olmstead and Tukey, 1947). In order to correct for multiple comparisons, the $\alpha$ value for significance was adjusted by Bonferroni corrections in both, the coaction and reciprocity experiments, for the Olmstead corner tests for digging coordination, as each observation was divided in $10 \mathrm{~s}$ intervals $(\alpha=0.0008)$.

\section{Ethical Note}

All fish were daily monitored for aberrant behavior and illness. We did not detect any of this during the course of the experiments. The experimental compartments were providing ample space for each test fish. In order to minimize stress levels, the test fish had permanent visual contact with each other between the experimental days. Moreover, they were visually separated from the predator stimulus fish (L. elongatus) used in the coaction experiment in order to prevent stress. As mentioned above, several trials were terminated and excluded from the experiments due to high levels of aggression between the social partners; however, as they were physically separated from each other by a clear partition, all aggression was confined to threat displays and physical contact with the Plexiglas partition. All experiments have been approved by the LANAT of the Canton Bern (License no. 40/05).

\section{RESULTS}

\section{Coaction}

In the Coaction Experiment, total digging frequencies of both test fish were negatively correlated with each other, indicating that if one fish invested much in sand removal, its partner invested less in this behavior ("partner digging frequency," Model 1, Table 1). 
TABLE 3 | Focal individuals' digging frequency, the correlation of digging between both fish, interval between subsequent digging bouts, and the latency to start a digging bout after the experimental partner had finished an own bout depending on experimental treatment (defection, help), experimental phase (experience, test), and social partner.

\begin{tabular}{|c|c|c|c|c|}
\hline Parameter & z-value & $P$-value & \multicolumn{2}{|c|}{ Coefficient \pm SE } \\
\hline \multicolumn{5}{|c|}{ Model 1: Digging frequency of focal fish } \\
\hline Intercept & 1.954 & 0.051 & 1.023 & 0.523 \\
\hline Treatment & 1.131 & 0.258 & 0.808 & 0.714 \\
\hline Phase & 7.533 & $<0.001$ & 0.714 & 0.095 \\
\hline Treatment * Phase & -1.392 & 0.164 & -0.159 & 0.115 \\
\hline \multicolumn{5}{|c|}{ Model 2: Correlation of digging between both fish } \\
\hline Intercept & 4.018 & $<0.001$ & 1.861 & 0.463 \\
\hline Helper digging freq & -0.033 & 0.974 & -0.0001 & 0.005 \\
\hline \multirow[t]{2}{*}{ Phase } & 6.109 & $<0.001$ & TH: 0.534 & 0.087 \\
\hline & -0.718 & 0.473 & TD: -0.579 & 0.806 \\
\hline \multirow[t]{2}{*}{ Helper digging freq * Phase } & 0.245 & 0.806 & TH: 0.001 & 0.003 \\
\hline & 1.314 & 0.189 & TD: 0.027 & 0.021 \\
\hline \multicolumn{5}{|c|}{ Model 3: Interval between subsequent digging bouts of focal fish } \\
\hline Intercept & 25.290 & $<0.001$ & 4.845 & 0.191 \\
\hline Treatment & -3.380 & $<0.001$ & -0.881 & 0.261 \\
\hline Phase & -33.270 & $<0.001$ & -0.932 & 0.028 \\
\hline Treatment * Phase & 19.120 & $<0.001$ & 0.757 & 0.040 \\
\hline \multicolumn{5}{|c|}{ Model 4: Latency of focal to start digging bout after a bout of the helper } \\
\hline Intercept & 11.256 & $<0.001$ & 2.916 & 0.259 \\
\hline \multirow[t]{2}{*}{ Phase } & -12.142 & $<0.001$ & TH: -0.582 & 0.048 \\
\hline & 0.668 & 0.504 & TD: 0.261 & 0.391 \\
\hline
\end{tabular}

Experimental treatment, phase, and their interaction were used as fixed effects (Models 1 and 2). For Models 3 and 4 experimental phase (experience help, EH; test help, TH; test defection, TD) were added as fixed effects. Digging frequency of the social partner ("helper") was used as a covariate. In all four models group identity was used as random effect.

All models were fitted by the Laplace approximation. Defection treatment, experience phase (Models 1 and 3), and experience phase of the helping treatment (Models 3 and 4) were used as reference categories with their coefficients set to zero. Digging frequency of the social partner ("helper") was treated as covariate. Significant p-values at an $\alpha$-level of 0.05 are shown in bold.

Generally, digging frequencies were higher during phases when the partner was visible compared to when there was no visual contact. In addition, the increase in digging frequencies was significantly influenced by the perceived risk of predation. If partners were able to observe each other, this increase was less steep than if they were not able to observe their partner (“presentation predator * partner visibility," Model 1, Table 1; Figure 2).

\section{Reciprocity}

The digging frequencies of focal fish were significantly higher in the test phase than in the experience phase, however this increase was not influenced by the partner's digging activity ("interaction Treatment * phase," Model 1, Table 3; Figure 3A). The digging efforts between the two animals were not correlated between each other in any of the three experimental phases where both fish were allowed to dig (experience "help," test "help" and test "defect"; "interaction helper digging freq * phase," Model 2, Table 3).

Nevertheless, in contrast to the frequencies of digging the time intervals between two subsequent digging bouts were strongly influenced by the previous digging behavior of the focal individuals' partners. The intervals between two digging bouts were generally longer if focal individuals experienced that their partners had not participated in digging (defection treatment) compared to the condition in which the partner had participated (helping treatment). Additionally, the difference in interval length between the two experimental phases of the focal fish was much larger in the defection treatment compared to the helping treatment ("interaction treatment * phase," Model 3, Table 3; Figure 3B).

Furthermore, focal animals waited for a longer period of time until they started a digging bout after their partner finished a digging bout in the test phase, if the partner had not participated in digging in the preceding experience phase than if it had ("phase," Model 4, Table 3; Figure 4).

\section{Temporal Coordination}

The test fish temporally coordinated their digging behavior when they could see each other during the first digging trial, i.e., they dug simultaneously in this phase ("Sand 1," Olmstead test; $k=$ $18, p=0.0002$ ). They did not coordinate their digging effort in the other phases of the coaction experiment (Olmstead test, "Control": $k=2, p=0.713$; "Sand 2": $k=0, p=0.926$; "Sand 3": $k=5, p=0.217$ ).

In the Reciprocity Experiment, the total digging frequencies were not correlated between the two test fish ("digging partner," Model 1, Table 3). To test for temporal coordination in digging between the test fish, $10 \mathrm{~s}$ intervals revealed a significant temporal coordination between the partners in both phases of the helping treatment (Olmstead test "Experience": $k=64, p<0.0001$; "Test": $k=134, p<0.0001)$, which did not apply to the test phase of the defection treatment.

The test for potential coordination of aggressive behaviors (displays and overt aggression) against the predator during the predator presentations revealed a significant correlation of the total aggression frequencies between the two partners, whereby the direction of this correlation depended on partner visibility. If the partner was not visible, this correlation was positive, whereas it was negative if they could see each other ("partner aggression * partner visibility," Model 3, Table 2). If the total observation time was divided into $10 \mathrm{~s}$ intervals, the data revealed that antipredator defense was temporally coordinated both when the test fish could see each other (Olmstead test; $k=77, p<0.0001$ ) and when not (Olmstead test; $k=163, p<0.0001$ ). The same pattern appeared in their hiding behavior: hiding in the shelter was coordinated both when the fish could see each other in the "Predator 1 " phase (Olmstead test; $k=112, p<0.0001$ ) and when the partner was not visible in the "Predator 2" phase of the experiment (Olmstead test; $k=103, p<0.0001$ ).

Without being exposed to a predator, the test fish coordinated their close distance approaches to the shelter entrances significantly more often when they saw each other than when 


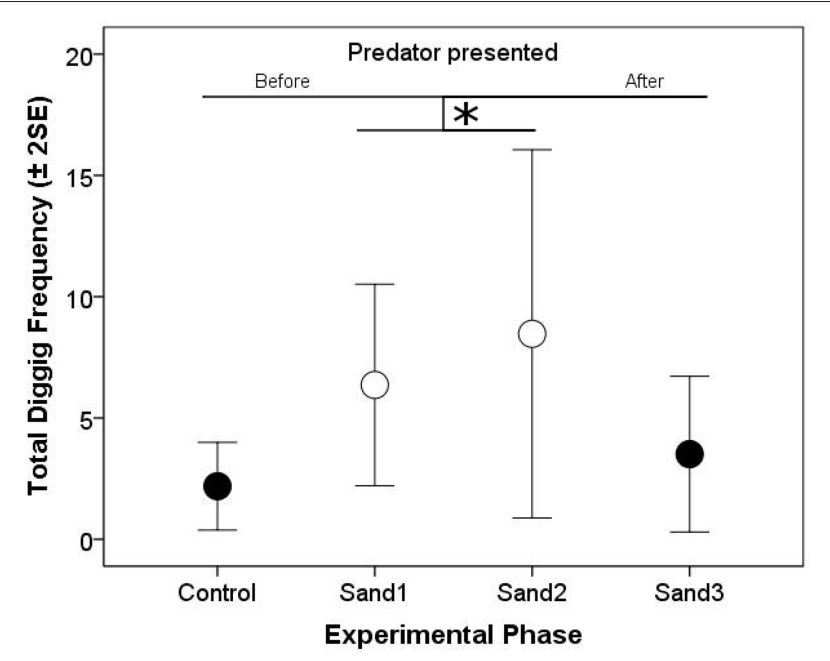

FIGURE 2 | Arithmetic means of total digging frequencies ( \pm 2 Standard errors of the mean; both focal fish and treatments combined) per 10 min of the "Control," "Sand 1," "Sand 2," and "Sand 3" phases of the Coaction Experiment. Solid circles represent experimental phases without visual contact between the test fish ("Control," "Sand 3") and open circles represent experimental phases with visual contact between them ("Sand 1," "Sand 2"). Significant differences are depicted by horizontal lines and an asterisk $(p<0.05)$.

they did not ("Control" vs. "Sand 1": Wilcoxon test; $N=14$, $z=-2.017, p=0.044$ ). In addition, after being exposed to a predator, fish with visual contact were more often simultaneously approaching shelter entrances closely compared to before being exposed to the predator ("Sand 1" vs. "Sand 2": Olmstead test; $k=11, p=0.034)$. When the focal test fish had no visual contact to each other, there was no difference in coordination of close distance shelter approaches before and after the predator exposure ("Control" vs. "Sand 3": Olmstead test; $k=1.5, p=0.836)$.

\section{DISCUSSION}

Here we investigated whether cooperative behaviors are contingent on each other's efforts among social partners sharing a territory and shelter, testing experimentally both for concurrent (coaction) and sequential (reciprocity) conditionality by manipulating the experimental subjects' behavior. We found that the cooperative effort of individuals in the social cichlid $N$. pulcher is indeed determined by the cooperative investment in territory maintenance behaviors exhibited by a social partner. However, in contrast to the predictions of continuous-time iterated game models of cooperation (van Doorn et al., 2014), the test subjects did not increase their digging effort immediately in response to their partner's investment in this behavior; in other words, digging out a common shelter did not reflect coaction. Instead, individuals reduced their total digging effort if their partner invested a lot in this duty, implying that they economized in this energetically highly demanding behavior (Grantner and Taborsky, 1998). This resembles a situation referred to as the

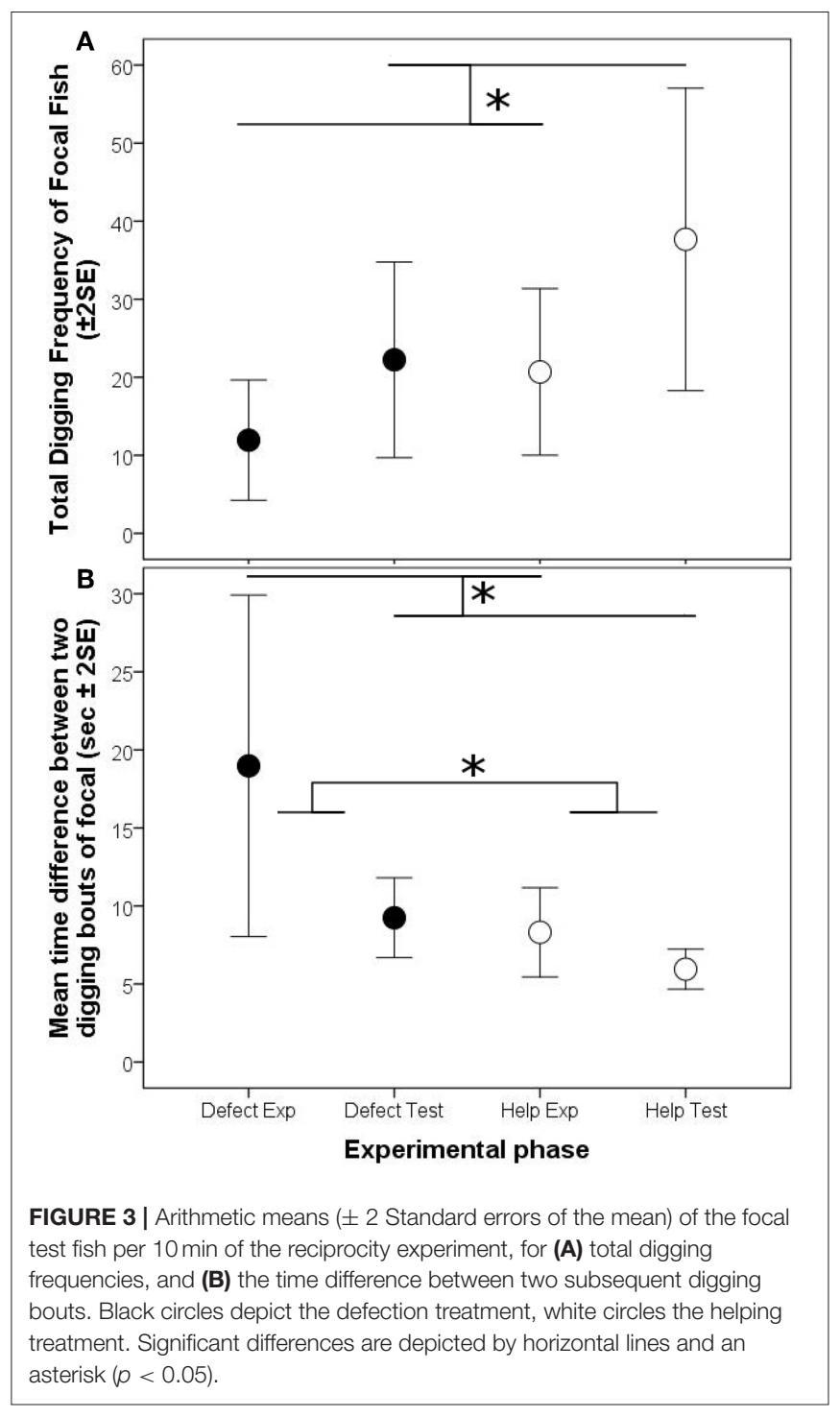

"tragedy of the commune," where some individuals benefit from the investment of others, if the behavior creates mutual benefits and the payoff matrix conforms with the snowdrift game (Doebeli et al., 2004). Remarkably, the resulting investment asymmetry between social partners emerged despite the fact that both partners increased their digging effort when they could see each other compared to the situation in which they could not.

In contrast to the results of the coaction experiment, there were positive long-term effects of the digging effort of an individual on that of its partner. The reciprocity experiment revealed that individuals started digging earlier and they made shorter breaks between digging bouts when their partners had engaged in digging in the previous experience phase. This indicates the use of decision rules characterizing direct reciprocity (Trivers, 1971; Taborsky et al., 2016). The contingency of an individual's cooperative effort, which creates mutual benefits, on a partner's previous investment in the same duty, 


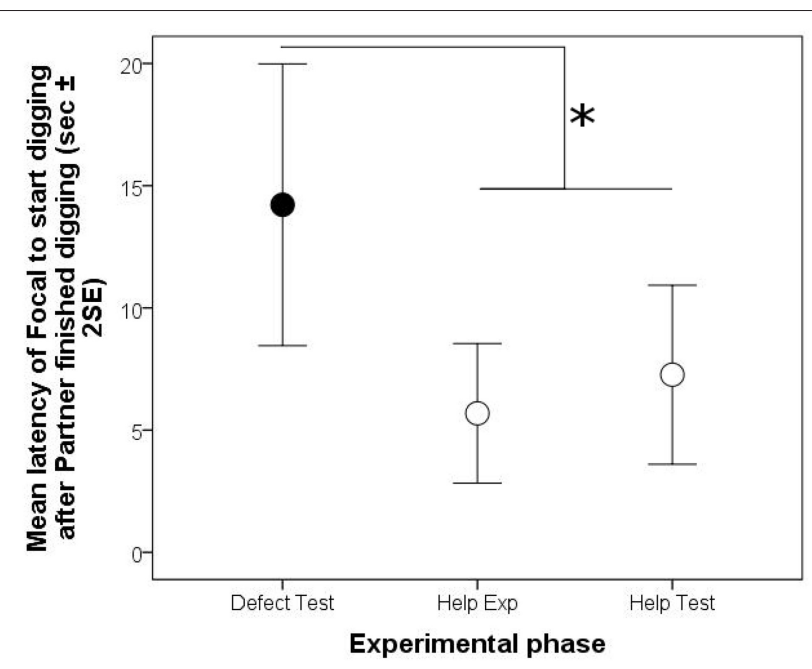

FIGURE 4 | Arithmetic means ( \pm 2 Standard errors of the mean) of time intervals in the reciprocity experiment between the end of a digging bout of the social partner and the start of a digging bout of the focal fish in the experience (Exp) and test (Test) phases of the helping (white circles) and defection treatments (black circles). Significant differences are depicted by horizontal lines and an asterisk $(p<0.05)$.

resembles the turn-taking of parents cooperatively provisioning their young, even if in such context the mutual monitoring of partners has been assumed to be imperfect (Johnstone et al., 2014; Johnstone and Savage, 2019). The contingency we found suggests that fish, too, can reciprocate a social partner's cooperative effort in a prisoner's dilemma situation, as has been suggested for birds (Stephens et al., 2002; Olendorf et al., 2003; Krams et al., 2008; St-Pierre et al., 2009) and mammals (Hemelrijk and Ek, 1991; Hart and Hart, 1992; Stopka and Graciasova, 2001; Rutte and Taborsky, 2008; Schino and Aureli, 2008; Carter and Wilkinson, 2013; Schweinfurth and Taborsky, 2017; Gfrerer and Taborsky, 2018; Kern and Radford, 2018; see Taborsky et al., 2016 for review). This may be particularly important in highly social species where members of groups should prevent being exploited by partners refusing to reciprocate cooperative behaviors from which they themselves benefit.

The behavioral contingency in the digging effort of our test fish involved a strong temporal coordination in both experiments testing for coaction and reciprocity, respectively. If the social partners had visual contact to each other when digging out a shared shelter, they coordinated their digging behavior both in time and frequency, which was not the case if the test fish could not see each other. Generally, digging frequencies were higher if the partner was visible, which might suggest social facilitation. However, contrasting to predictions of social facilitation theory (Sanders, 1981; Reynaud et al., 2015), coordination in frequency was negative if the partner was visible, as outlined above. Temporal coordination occurred within short time intervals, whereas no correlations in total digging frequencies were found when longer time periods were considered $(10 \mathrm{~min})$. Temporal coordination of digging behavior clearly emerged in the first test period with visual contact ("Sand 1"). Also in the reciprocity experiment, the test fish temporally coordinated digging in two out of three phases in which both individuals were enabled to dig. As predicted, there was no coordination in the experimental phase after the social partner had been prevented to participate in digging.

In accordance with prediction, the fish dug more often after witnessing danger by a presented predator. Nevertheless, digging frequencies did not increase after predator exposure when the partners saw each other, so cooperation did not ensue in response to perceived predation risk, as was found to occur between neighbors in pied flycatchers (Ficedula hypoleuca; Krams et al., 2010). This might indicate that the fish did not solve the "tragedy of the commons" dilemma (Hardin, 1968) in this situation, i.e., they may economize on digging effort, which is energetically demanding (Grantner and Taborsky, 1998) and can increase mortality risk in this situation.

We should like to point out that the absolute digging frequencies differed between the two experiments. This was most probably due to a difference in the pre-experimental acclimatization phase of these two experiments. In the reciprocity experiment, the fish were exposed to a digging demand repeatedly by filling their common shelter before the experiment started (see Methods section for details). This procedure was not carried out in the coaction experiment where the test subjects experienced enhanced digging demands for the first time on the experimental day. This may explain their overall rather low digging effort. These differences in procedures during the acclimatization periods imply that the absolute digging effort should not be compared between the two experiments.

Not only digging, but also spacing and shelter visits were coordinated between partners of experimental dyads when they could see each other, which was enhanced after predator exposure. This indicates that the fish prefer spatial proximity to social partners, especially in case of perceived danger. In the field, helpers in family groups also stay closer to the shelter in case of enhanced predation risk (Heg et al., 2004; Heg and Taborsky, 2010). The fish visited the shelter more often in the presence of a predator when they had visual contact with each other than when they had none. This suggests that (i) they do not behave as if they were aware of benefitting from "safety in numbers," (ii) they are probably not saving vigilance effort by coordinating their behavior, such as Defassa waterbuck do for example (Kobus ellipsiprymnus defassa; Pays et al., 2007), (iii) they might compete for access to shelter, thereby attempting to improve their survival chances relative to a social partner, which again suggests that they do not solve the "tragedy of the commons" dilemma in this situation.

Furthermore, defense against the presented predator was also coordinated between the social partners. Interestingly, total antipredator aggression correlated positively when the fish could not see each other, whereas it correlated negatively with each other when they had visual contact. This might hint on two divergent underlying causes. The positive correlation between antipredator aggression when the partners could not see each other hints at an influence of the predator cue, indicating that the two test fish have perceived the potential threat entailed by the predator similarly. By contrast, the negative correlation between 
the test subjects' antipredator aggression when they could see each other points toward economizing in a "tragedy of the commune" situation as modeled by the snowdrift game (Doebeli et al., 2004). Similarly to the saving of energetic expenditure by reducing digging when the partner engages in digging out the common shelter, an individual can reduce its own predation risk when holding back from attacks against a dangerous predator while a social partner is expelling it anyway. Close temporal coordination of the antipredator behavior of the social partners was revealed when the recording time was split into $10 \mathrm{~s}$ intervals. This might have resulted from both the predator's and the partner's behavior, as coordination occurred both in the visual contact and the visual isolation situations.

In conclusion, our results provide evidence that when fish are exposed to a situation where a behavior can generate mutual benefits among social partners, they may show (i) precise temporal coordination of their actions, (ii) reduce own investment if their partner fulfills the duty, i.e., somewhat free ride on the partner's effort in a situation resembling the snowdrift game, and (iii) reciprocate help received in a previous time period in a situation resembling the sequential prisoner's dilemma game. Our study cannot answer for how long this enhancing effect of previously received help on the cooperation propensity of test subjects would persist, and we do not know whether different commodities, such as territory maintenance and defense, may be traded against each other in an iterated prisoner's dilemma situation (cf. Schweinfurth and Taborsky, 2018). Nevertheless, previous studies have demonstrated reciprocal trading among groups of helpers and breeders in our study species, where individuals pay to be allowed to stay in a safe territory (Taborsky, 1985; Bergmüller and Taborsky, 2005; Heg and Taborsky, 2010; Zöttl et al., 2013; Fischer et al., 2014). Our study hence confirms that the cooperatively breeding cichlid $N$. pulcher is

\section{REFERENCES}

Balshine, S., Leach, B., Neat, F., Reid, H., Taborsky, M., and Werner, N. (2001). Correlates of group size in a cooperatively breeding cichlid fish. Behav. Ecol. Sociobiol. 50, 134-140. doi: 10.1007/s002650100343

Balshine-Earn, S., and Lotem, A. (1998). Individual recognition in a cooperatively breeding cichlid: evidence from video playback experiments. Behaviour 135, 369-386. doi: 10.1163/156853998793066221

Barta, Z., McNamara, J. M., Huszár, D. B., and Taborsky, M. (2011). Cooperation among non-relatives evolves by state-dependent generalized reciprocity. Proc. R. Soc. B Biol. Sci. 278, 843-848. doi: 10.1098/rspb.201 0.1634

Bates, D., and Maechler, M. (2010). Linear Mixed-Effects Models Using S4 Classes. R Package Version 0.999375-35. Vienna: R Foundation for statistical Computing.

Bergmüller, R., Heg, D., and Taborsky, M. (2005). Helpers in a cooperatively breeding cichlid stay and pay or disperse and breed, depending on ecological constraints. Proc. R. Soc. Lond. B 272, 325-331. doi: 10.1098/rspb.2004.2960

Bergmüller, R., and Taborsky, M. (2005). Experimental manipulation of helping in a cooperative breeder: helpers 'pay to stay' by pre- emptive appeasement. Anim. Behav. 69, 19-28. doi: 10.1016/j.anbehav.2004.05.009

Brouwer, L., Heg, D., and Taborsky, M. (2005). Experimental evidence for helper effects in a cooperatively breeding cichlid. Behav. Ecol. 16, 667-673. doi: 10.1093/beheco/ari042

Brown, C., and Laland, K. N. (2003). Social learning in fishes: a review. Fish Fish. 4, 280-288. doi: 10.1046/j.1467-2979.2003.00122.x an excellent model species to investigate reciprocal cooperation in an evolutionary context involving both, simultaneous and sequential interactions and the trading of commodities (cf. Taborsky, 1987; Bergmüller et al., 2005; Bruintjes and Taborsky, 2011; Quinones et al., 2016). To our knowledge, this is the first experimental report revealing contingent sequential cooperation in a cooperatively breeding vertebrate.

\section{DATA AVAILABILITY STATEMENT}

All datasets generated for this study are included in the article/supplementary material.

\section{ETHICS STATEMENT}

The animal study was reviewed and approved by Veterinary Office of the Canton Bern, Switzerland.

\section{AUTHOR CONTRIBUTIONS}

MT conceived the study. MT and TR designed the experiments and wrote the manuscript. TR collected and analyzed the data with help of MT, and drew the figures.

\section{ACKNOWLEDGMENTS}

We acknowledge the support of the Swiss National Science Foundation (project grants 30100A0-105626, 31003A-122511, and $31003 \mathrm{~A}-176174$ to MT). We are grateful to our colleagues at the Hasli for discussion, and Arne Jungwirth for helpful comments and contributions to the manuscript. Moreover, we thank Rick Bruintjes and Dik Heg for help in handling and measuring the fish.
Bruintjes, R., and Taborsky, M. (2011). Size-dependent task specialization in a cooperative cichlid in response to experimental variation of demand. Anim. Behav. 81, 387-394. doi: 10.1016/j.anbehav.2010.10.004

Carter,G. G., and Wilkinson,G.S. (2013). Food sharing in vampire bats: reciprocal help predicts donations more than relatedness or harassment. Proc. R. Soc. B Biol. Sci. 280:20122573. doi: 10.1098/rspb.2012.2573

Clutton-Brock, T. H., Brotherton, P. N. M., Russel, A. F., O’Rian, M. J., Gaynor, D., Kansky, R., et al. (2001). Cooperation, control, and concession in meerkat groups. Science 291, 477-481. doi: 10.1126/science.291.5503.478

Coussi-Korbel, S., and Fragaszy, D. M. (1995). On the relation between social dynamics and social learning. Anim. Behav. 50, 1441-1453. doi: 10.1016/0003-3472(95)80001-8

Dierkes, P., Heg, D., Taborsky, B., Skubic, E., and Achmann, R. (2005). Genetic relatedness in groups is sex-specific and declines with age of helpers in a cooperatively breeding cichlid. Ecol. Lett. 8, 968-975. doi: 10.1111/j.1461-0248.2005.00801.x

Doebeli, M., Hauert, C., and Killingback, T. (2004). The evolutionary origin of cooperators and defectors. Science 306, 859-862. doi: 10.1126/science.1101456

Duftner, N., Sefc, K. M., Kolbmüller, S., Salzburger, W., Taborsky, M., and Sturmbauer, C. (2007). Parallel evolution of facial stripe patterns in the Neolamprologus brichardi/pulcher species complex endemic to Lake Tanganyika. Mol. Phylogenet. Evol. 45, 706-715. doi: 10.1016/j.ympev.2007.08.001

Dugatkin, L. A. (1997). Cooperation Among Animals: An Evolutionary Perspective. New York, NY: Oxford University Press. 
Dugatkin, L. A. (2002). Animal cooperation among unrelated individuals. Naturwissenschaften 89, 533-541. doi: 10.1007/s00114-002-0379-y

Eberle, M., and Kappeler, P. M. (2006). Family insurance: kin selection and cooperative breeding in a solitary primate (Microcebus murinus). Behav. Ecol. Sociobiol. 60, 582-588. doi: 10.1007/s00265-006-0203-3

Fernandez-Juricic, E., Kerr, B., Bednekoff, P. A., and Stephens, D. W. (2004). When are two heads better than one? Visual perception and information transfer affect vigilance coordination in foraging groups. Behav. Ecol. 15, 898-906. doi: 10.1093/beheco/arh092

Fischer, S., Zöttl, M., Groenewoud, F., and Taborsky, B. (2014). Groupsize-dependent punishment of idle subordinates in a cooperative breeder where helpers pay to stay. Proc. R. Soc. B Biol. Sci. 281:20140184. doi: $10.1098 /$ rspb.2014.0184

Galloway, A. T., Addessi, E., Fragaszy, D. M., and Visalberghi, E. (2005). Social facilitation of eating familiar food in tufted capuchins (Cebus apella): does it involve behavioral coordination? Int. J. Primatol. 26, 181-189. doi: 10.1007/s10764-005-0729-7

Gashagaza, M. M. (1988). Feeding activity of a Tanganyikan cichlid fish, Lamprologus brichardi. Afr. Study Monogr. 9, 1-9.

Gfrerer, N., and Taborsky, M. (2017). Working dogs cooperate among one another by generalised reciprocity. Sci. Rep. 7:43867. doi: 10.1038/srep43867

Gfrerer, N., and Taborsky, M. (2018). Working dogs transfer different tasks in reciprocal cooperation. Biol. Lett. 14:20170460. doi: 10.1098/rsbl.2017.0460

Grantner, A., and Taborsky, M. (1998). The metabolic rates associated with resting, and with the performance of agonistic, submissive and digging behaviours in the cichlid fish Neolamprologus pulcher (Pisces: Cichlidae). J. Comp. Physiol. B 168, 427-433. doi: 10.1007/s003600050162

Groenewoud, F., Frommen, J. G., Josi, D., Tanaka, H., Jungwirth, A., and Taborsky, M. (2016). Predation risk drives social complexity in cooperative breeders. Proc. Natl. Acad. Sci. U.S.A. 113, 4104-4109. doi: 10.1073/pnas.1524178113

Hall, M. L., and Peters, A. (2008). Coordination between the sexes for territorial defence in a duetting fairy-wren. Anim. Behav. 76, 65-73. doi: 10.1016/j.anbehav.2008.01.010

Hamilton, I. M., and Taborsky, M. (2005). Contingent movement and cooperation evolve under generalized reciprocity. Proc. R. Soc. B Biol. Sci. 272, 2259-2267. doi: 10.1098/rspb.2005.3248

Hardin, G. (1968). Tragedy of commons. Science 162, 1243-1248. doi: $10.1126 /$ science.162.3859.1243

Hart, B. L., and Hart, L. A. (1992). Reciprocal allogrooming in impala, Aepyceros melampus. Anim. Behav. 44, 1073-1083. doi: 10.1016/S0003-3472(05) 80319-7

Heg, D., Bachar, Z., Brouwer, L., and Taborsky, M. (2004). Predation risk is an ecological constraint for helper dispersal in a cooperatively breeding cichlid. Proc. R. Soc. Lond. B 271, 2367-2374. doi: 10.1098/rspb.2004.2855

Heg, D., Brouwer, L., Bachar, Z., and Taborsky, M. (2005). Large group size yields group stability in the cooperatively breeding cichlid Neolamprologus pulcher. Behaviour 142, 1615-1641. doi: 10.1163/156853905774831891

Heg, D., and Taborsky, M. (2010). Helper response to experimentally manipulated predation risk in the cooperatively breeding cichlid Neolamprologus pulcher. PLOS ONE 5:e10784. doi: 10.1371/journal.pone.0010784

Hemelrijk, C. K., and Ek, A. (1991). Reciprocity and interchange of grooming and support in captive chimpanzees. Anim. Behav. 41, 923-935. doi: 10.1016/S0003-3472(05)80630-X

Hert, E. (1985). Individual recognition of helpers by the breeders in the cichlid fish Lamprologus brichardi (Poll, 1974). Z. Tierpsychol. 68, 313-325. doi: 10.1111/j.1439-0310.1985.tb00132.x

Johnstone, R. A., Manica, A., Fayet, A. L., Stoddard, M. C., Rodriguez-Girones, M. A., and Hinde, C. A. (2014).. Reciprocity and conditional cooperation between great tit parents. Behav. Ecol. 25, 216-222. doi: 10.1093/beheco/art109

Johnstone, R. A., and Savage, L. (2019). Conditional cooperation and turn-taking in parental care. Front. Ecol. Evol. 7:335. doi: 10.3389/fevo.2019.00335

Jungwirth, A., Josi, D., Walker, J., and Taborsky, M. (2015). Benefits of coloniality: communal defence saves anti-predator effort in cooperative breeders. Funct. Ecol. 29, 1218-1224. doi: 10.1111/1365-2435.12430

Karplus, I., Zion, B., Rosenfeld, L., Grinshpun, Y., Slosman, T., Goshen, Z., et al. (2007). Social facilitation of learning in mixed-species schools of common carp Cyprinus carpio L. and Nile tilapia Oreochromis niloticus (L.). J. Fish Biol. 71, 1023-1034. doi: 10.1111/j.1095-8649.2007.01568.x
Kern, J. M., and Radford, A. N. (2018). Experimental evidence for delayed contingent cooperation among wild dwarf mongooses. Proc. Natl. Acad. Sci. U.S.A. 115, 6255-6260. doi: 10.1073/pnas. 1801000115

Krams, I., Berzins, A., Krama, T., Wheatcroft, D., Igaune, K., and Rantala, M. J. (2010). The increased risk of predation enhances cooperation. Proc. R. Soc. Lond. B 277, 513-518. doi: 10.1098/rspb.2009.1614

Krams, I., Krama, T., Igaune, K., and Mand, R. (2008). Experimental evidence of reciprocal altruism in the pied flycatcher. Behav. Ecol. Sociobiol. 62, 599-605. doi: 10.1007/s00265-007-0484-1

Lehmann, L., and Keller, L. (2006). The evolution of cooperation and altruism-a general framework and a classification of models. J. Evol. Biol. 19, 1365-1376. doi: 10.1111/j.1420-9101.2006.01119.x

Lewis, S., Schreiber, E. A., Daunt, F., Schenk, G. A., Wanless, S., and Hamer, K. C. (2004). Flexible foraging patterns under different time constraints in tropical boobies. Anim. Behav. 68, 1331-1337. doi: 10.1016/j.anbehav.2004.04.007

Milinski, M., and Wedekind, C. (1998). Working memory constrains human cooperation in the Prisoner's Dilemma. Proc. Natl. Acad. Sci. USA. 95, 13755-13758. doi: 10.1073/pnas.95.23.13755

Nowak, M. A., and Roch, S. (2007). Upstream reciprocity and the evolution of gratitude. Proc. R. Soc. B Biol. Sci. 274, 605-610. doi: 10.1098/rspb.2006.0125

Olendorf, R., Getty, T., and Scribner, K. (2003). Cooperative nest defence in redwinged blackbirds: reciprocal altruism, kinship or by-product mutualism? Proc. R. Soc. Lond. B 271, 177-182. doi: 10.1098/rspb.2003.2586

Olmstead, P. S., and Tukey, J. W. (1947). A corner test for association. Ann. Math. Stat. 18, 495-513. doi: 10.1214/aoms/1177730341

Pays, O., Renaud, P. C., Loisel, P., Petit, M., Gerard, J. F., and Jarman, P. J. (2007). Prey synchronize their vigilant behaviour with other group members. Proc. $R$. Soc. Lond. B 274, 1287-1291. doi: 10.1098/rspb.2006.0204

Pfeiffer, T., Rutte, C., Killingback, T., Taborsky, M., and Bonhoeffer, S. (2005). Evolution of cooperation by generalized reciprocity. Proc. R. Soc. B Biol. Sci. 272, 1115-1120. doi: 10.1098/rspb.2004.2988

Quinones, A. E., van Doorn, G. S., Pen,I., Weissing, F. J., and Taborsky, M. (2016). Negotiation and appeasement can be more effective drivers of sociality than kin selection. Philos. Trans. R. Soc. B Biol. Sci. 371:20150089. doi: 10.1098/rstb.2015.0089

Rankin, D. J., and Taborsky, M. (2009). Assortment and the evolution of generalized reciprocity. Evolution 63, 1913-1922. doi: $10.1111 / j .1558-5646.2009 .00656 . x$

Reynaud, A. J., Guedj, C., Hadj-Bouziane, F., Meunier, M., and Monfardini, E. (2015). Social facilitation of cognition in rhesus monkeys: audience vs. coaction. Front. Behav. Neurosci. 9:328. doi: 10.3389/fnbeh.2015.00328

Rutte, C., and Taborsky, M. (2007). Generalized reciprocity in rats. PLoS Biol. 5, 1421-1425. doi: 10.1371/journal.pbio.0050196

Rutte, C., and Taborsky, M. (2008). The influence of social experinece on cooperative behaviour of rats (Rattus norvegicus): direct vs generalized reciprocity. Behav. Ecol. Sociobiol. 62, 499-505. doi: $10.1007 / \mathrm{s} 00265-007-0474-3$

Sanders, G. S. (1981). Driven by distraction - an integrative review of social facilitation theory and research. J. Exp. Soc. Psychol. 17, 227-251. doi: 10.1016/0022-1031(81)90024-X

Schino, G., and Aureli, F. (2008). Trade-offs in primate grooming reciprocation: testing behavioural flexibility and correlated evolution. Biol. J. Linn. Soc. 95, 439-446. doi: 10.1111/j.1095-8312.2008.01067.x

Schweinfurth, M. K., and Taborsky, M. (2017). The transfer of alternative tasks in reciprocal cooperation. Anim. Behav. 131, 35-41. doi: 10.1016/j.anbehav.2017.07.007

Schweinfurth, M. K., and Taborsky, M. (2018). Reciprocal trading of different commodities in Norway rats. Curr. Biol. 28, 594-599. doi: 10.1016/j.cub.2017.12.058

Stephens, D. W., McLinn, C. M., and Stevens, J. R. (2002). Discounting and reciprocity in an iterated Prisoner's Dilemma. Science 298, 2216-2218. doi: $10.1126 /$ science. 1078498

Stevens, J. R., Cushman, F. A., and Hauser, M. D. (2005). Evolving the psychological mechanisms for cooperation. Annu. Rev. Ecol. Evol. Syst. 36, 499-518. doi: 10.1146/annurev.ecolsys.36.113004.083814

Stevens, J. R., and Hauser, M. D. (2004). Why be nice? Psychological constraints on the evolution of cooperation. Trends Cogn. Sci. 8, 60-65. doi: $10.1016 /$ j.tics.2003.12.003 
Stiver, K. A., Dierkes, P., Taborsky, M., Gibbs, H. L., and Balshine, S. (2005). Relatedness and helping in fish: examining the theoretical predictions. Proc. $R$. Soc. Lond. B 272, 1593-1599. doi: 10.1098/rspb.2005.3123

Stojkoski, V., Utkovski, Z., Basnarkov, L., and Kocarev, L. (2018). Cooperation dynamics of generalized reciprocity in state-based social dilemmas. Phys. Rev. E 97:052305. doi: 10.1103/PhysRevE.97.052305

Stopka, P., and Graciasova, R. (2001). Conditional allogrooming in the herb-field mouse. Behav. Ecol. 12, 584-589. doi: 10.1093/beheco/1 2.5.584

St-Pierre, A., Larose, K., and Dubois, F. (2009). Long-term social bonds promote cooperation in the iterated Prisoner's Dilemma. Proc. R. Soc. Lond. B 276, 4223-4228. doi: 10.1098/rspb.2009.1156

Székely, T., Moore, A. J., and Komdeur, J. (2010). Social Behaviour: Genes, Ecology and Evolution. New York, NY: Cambridge University Press.

Taborsky, M. (1984). Broodcare helpers in the cichlid fish Lamprologus brichardi: their costs and benefits. Anim. Behav. 32, 1236-1252. doi: 10.1016/S0003-3472(84)80241-9

Taborsky, M. (1985). Breeder-helper conflict in a cichlid fish with broodcare helpers - an experimental analysis. Behaviour 95, 45-75. doi: $10.1163 / 156853985 X 00046$

Taborsky, M. (1987). "Cooperative behaviour in fish: coalitions, kin groups and reciprocity," In Animal Societies: Theories and Facts, eds J. L. Brown, I. Kikkawa (Tokyo, Japan Scientific Society Press), 229-237.

Taborsky, M. (2016). "Cichlid fishes: a model for the integrative study of social behavior," in Cooperative Breeding in Vertebrates, eds W. D. Koenig, J. L. Dickinson (Cambridge, UK: Cambridge University Press), 272-293.

Taborsky, M., and Frommen,J. G., Riehl,C. (2016). Correlated pay-offs are key to cooperation. Phil. Trans. R. Soc. B Biol.Sci. 371:20150084. doi: 10.1098/rstb.2015.0084
Taborsky, M., and Grantner, A. (1998). Behavioural time-energy budgets of cooperatively breeding Neolamprologus pulcher. Anim. Behav. 56, 1375-1382. doi: 10.1006/anbe.1998.0918

Taborsky, M., and Limberger, D. (1981). Helpers in fish. Behav. Ecol. Sociobiol. 8, 143-145. doi: 10.1007/BF00300826

Trivers, R. L. (1971). Evolution of reciprocal altruism. Q. Rev. Biol. 46, 35-57. doi: $10.1086 / 406755$

van Doorn, G. S., Riebli, T., and Taborsky, M. (2014). Coaction versus reciprocity in continous-time models of cooperation. J. Theor. Biol. 356, 1-10. doi: 10.1016/j.jtbi.2014.03.019

van Doorn, G. S., and Taborsky, M. (2012). The evolution of generalized reciprocity on social interaction networks. Evolution 66, 651-664. doi: 10.1111/j.1558-5646.2011.01479.x

Zajonc, R. B. (1965). Social facilitation. Science 149, 269-274. doi: $10.1126 /$ science.149.3681.269

Zöttl, M., Heg, D., Chervet, N., and Taborsky, M. (2013). Kinship reduces alloparental care in cooperative cichlids where helpers pay-to-stay. Nat. Commun. 4:1341. doi: 10.1038/ncomms2344

Conflict of Interest: The authors declare that the research was conducted in the absence of any commercial or financial relationships that could be construed as a potential conflict of interest.

Copyright $\odot 2020$ Taborsky and Riebli. This is an open-access article distributed under the terms of the Creative Commons Attribution License (CC BY). The use, distribution or reproduction in other forums is permitted, provided the original author(s) and the copyright owner(s) are credited and that the original publication in this journal is cited, in accordance with accepted academic practice. No use, distribution or reproduction is permitted which does not comply with these terms. 